\title{
Forecasting Techniques for Wheat Production in Sindh Province
}

\author{
Ali Akbar Pirzado ${ }^{1 *}$, Imran Khan Jatoi ${ }^{1}$, Muhammad Bux Shar ${ }^{2}$, Naeem Ahmed Qureshi ${ }^{2}$ Moula \\ Bux Peerzado ${ }^{3}$, Arman Khan Khanzada ${ }^{4}$, Ishfaque Ahmed Rahujo ${ }^{4}$, Rafique Ahmed Lakhan ${ }^{5}$ \\ ${ }^{1}$ Department of Statistics, Shaheed Benazir Bhutto University, Shaheed Benazirabad, Pakistan \\ ${ }^{2}$ Department of Statistics, Sindh Agriculture University, Tandojam Pakistan \\ ${ }^{3}$ Department of Agricultural Economic, Sindh Agriculture University Tandojam, Pakistan \\ ${ }^{4}$ Department of Business Administration, Shaheed Benazir Bhutto University, Shaheed \\ Benazirabad, Pakistan. \\ ${ }^{5}$ Department of English, Shaheed Benazir Bhutto University, Shaheed Benazirabad, Pakistan \\ *Corresponding: ali.akbar@sbbusba.edu.pk \\ Article Received 05-08-2020, Revised 21-09-2020, Accepted 25-09-2020
}

\begin{abstract}
:
The present study is an attempt to forecast the wheat production in Sindh province of Pakistan using sophisticated statistical techniques. The secondary data regarding area, production and yield of wheat crop were collected for the last thirty years (1984-85 to 2013-14) for estimation and forecasting purposes using time series techniques such as moving averages and exponential smoothing. The estimates for three, five and seven-years moving averages for area were found to have a minimum value of $849.87,863.04$, and 890.09 hectares and maximum value of 1129.4,1111.58, and 1109.6 hectares respectively. Likewise, for production, these estimates were found as 2065.57, 2117.7, 2154.3 and 3917.50, 3740.8, 3469.4 tons respectively. So, for as the yield is concerned, the above-mentioned estimates for minimum and maximum were found as 2071.7, 2107.8, 2121 and 3574.0, 3520, and 3414 respectively. Based on the findings of the present study, it is concluded that during the last thirty years the area, production and yield under wheat cultivation showed an increasing trend. In case of forecasting, the area and production under wheat cultivation was increase in the coming year, but the yield under wheat cultivation was considerably decreased due to shortage of irrigation water.
\end{abstract}

Keywords: Forecasting, irrigation water, production, Sindh, wheat crop

\section{Introduction}

Wheat is primary food item and accounts 8.9 percent value added in agriculture and 1.6 percent of GDP. Wheat crop showed marginal increase of 0.5 percent (GOP, 2019). The largest consumption of wheat is found in rural areas as compared to urban areas. From years wheat crop is affected by different factors such as; increases in the input prices, water shortages, etc., whereas good yields of wheat crops have been observed in recent past in Pakistan. Healthy strategic stocks can be brought together because of satisfactory conditions (GOP, 2015). Publications show that different researchers have worked on the formulation of a wheat forecasting model in Pakistan. Various studies were carried out by investigators in the decade of 1970s and 1980s when Pakistan faced harsh situations for staple foods. Inputs used in these models include labor, tractors, temperature, fertilizer and rainfall (Iqbal et al., 2005). Publications show that production of wheat would grow to 29.77 million tons in the year 2022 as estimated by ARIMA model (Iqbal et al., 2005). Many studies have been conducted to forecast and determine constraints in the production of major crops such as wheat, cotton and rice in Pakistan (Hamid and Ahmed, 2001, Masood et al. 2012). Despite these constraints, there are indeed good prospects for continued growth in the area and yield of wheat and other crops in Pakistan (Hamid et al., 1987; Muhammad, 1989; Qureshi et al. 1992) analyzed the relative contribution of area and yield to total production of wheat and maize in Pakistan and concluded that there was more than $100 \%$ increase in total wheat production that can be attributed to yield enhancement. (Muhammad et al. 1992) conducted an empirical study of modeling and forecasting time series data of rice production in Pakistan. ARIMA model has been frequently employed to forecast the future requirements in terms of internal consumption and 
export to adopt appropriate measures (Muhammad et al., 1992; Shabur and Haque, 1993; Sohail et al., 1994; Karim et al. 2005) applied regression modeling to forecast wheat production of Bangladesh districts. It is found by (Amin et al. $2014)$ that the best model is ARIMA $(1,2,2)$. On the basis of this selected model, it was found that wheat production of Pakistan would become 26623.5 thousand tons in 2020 and would become double in 2060 as compared in 2010 (Amin et al., 2014). Ups and downs have been observed in wheat production of Pakistan due to inappropriate marketing facilities as well as lack of knowledge to farmers regarding future prospect of wheat production and prices. It is important to forecast area, yield and production of wheat in Pakistan. Regression modeling was applied by Karim et al. (2005) to forecast wheat production in various districts of Bangladesh; however, they applied seven model selection criteria. ARIMA model was used for forecasting wheat area as well as production in Pakistan Kumar et al. (2019) and (Iqbal et al., 2000). ARIMA $(1,1,1)$ and ARIMA $(2,1,2)$ models were used for wheat area forecasting and wheat production forecasting respectively. For the year 2022; their forecast was 8475.1 thousand hectares. The function of this research study recommended production technology package for farmers and extension workers based on the significant factors identified through forecasting moving averages Shah et al. (2018) and Hasan et al. (2013). Besides, production trends were developed to know the percentage changes in availability of food grains especially of wheat. This study is helpful for researchers, extension educators, and policymakers for the food security for coming generations.

Material and Methods: In order to study the forecasting techniques for wheat production in Sindh province; a survey was performed to collect the information / data regarding wheat area, production and yield in Sindh Province from1984 to 2014. The data was collected from "Agriculture Statistics of Pakistan. The data for area, production and yield trends was studied using time series techniques, since the year 1984 to 2014

Statistical Analysis: Statistical package SPSS was used for data analysis. Moreover, Microsoft Excel was used for exponential smoothing. In the following section moving average, forecasting trend and exponential smoothing was briefly described.

Moving Averages: The Moving Averages methodology is utilized to process figures for time arrangement information. A moving normal (just mean or normal) is a calculation to research data focuses by making a movement method for various subsets of the full information set. At that point the $3,5,7$ years moving midpoints are underneath.

Chose $K$ to be even, say, $K=3$ years. Then the 3 years moving averages could be computed as,

Whereas,

$K=$ Numbers

$Y=$ Years

$a=$ Average

Where

$$
\hat{Y}_{t-1}=\left(Y_{t}+Y_{t-1}+\cdots Y_{t-p+1}\right) / p
$$

$\hat{\mathrm{Y}}_{t+1}$ is forecasted yield for year $\mathrm{t}+1, Y_{t}$ is reported yield for year $t$, and $p$ is the number of terms specified in the moving averaging technique. OR

$\mathbf{S M A}=\mathbf{Y}_{\mathbf{M}}+\mathbf{Y}_{\mathbf{M}-\mathbf{1}}+\cdots+\mathbf{Y}_{\mathbf{M}-(\mathbf{n}-1)} / \mathbf{n}=$ $\frac{1}{n} \sum_{i=0}^{n-1} P M-i$

$\mathbf{a}_{1}=1 / 3\left(\mathbf{Y}_{1}+\mathbf{Y}_{2}+\mathbf{Y}_{3}\right)$,

$a_{2}={ }_{1 / 3}\left(Y_{2}+Y_{3}+Y_{4}\right)$,

$\mathbf{a}_{3}={ }_{1 / 3}\left(\mathbf{Y}_{3}+\mathbf{Y}_{4}+\mathbf{Y}_{5}\right)$,

Chose $K$ to be even, say, $K=5$ years. Then the 5 years moving averages could be computed as,

$\mathbf{a}_{1}={ }_{1 / 5}\left(\mathbf{Y}_{1}+\mathbf{Y}_{2}+\mathbf{Y}_{3}+\mathbf{Y}_{4}+\mathbf{Y}_{5}\right)$,

$a_{2}={ }_{1 / 5}\left(Y_{2}+Y_{3}+Y_{4}+Y_{5}+Y_{6}\right)$

$a_{3}={ }_{1 / 5}\left(Y_{3}+Y_{4}+Y_{5}+Y_{6}+Y_{7}\right)$

We, chose $K$ to be even, say, $K=7$ years. Then the

7 years moving averages could be computed as

$a_{1}={ }_{1 / 7}\left(Y_{1}+Y_{2}+Y_{3}+Y_{4}+Y_{5}+Y_{6}+Y_{7}\right)$,

$a_{2}={ }_{1 / 7}\left(Y_{2}+Y_{3}+Y_{4}+Y_{5}+Y_{6}+Y_{7}+Y_{8}\right)$,

$a_{3}={ }_{1 / 7}\left(Y_{3}+Y_{4}+Y_{5}+Y_{6}+Y_{7}+Y_{8}+Y_{9}\right)$,

Exponential Smoothing: Exponential smoothing is Statistical technique for perceiving significant changes in data by ignoring the variations unrelated to the determination at hand. exponential smoothing is an as opposite to moving averages smoothing, it means older information is given progressively-less comparative weight (importance) whereas newer information is given progressively-greater weight. It is also named averaging and it is used in making short-term forecasts. The raw data sequence is often represented by $x_{t}$ beginning at time $\mathrm{t}=0$, and the output of the exponential smoothing algorithm is commonly written as $S_{t}$, which may be regarded as a best estimate of what the next value of $\mathrm{x}$ will be. When the sequence of observations begins at time $\mathrm{t}=0$, the simplest form of exponential smoothing is given by the formulas.

$s_{0}=x_{0}$

$s_{t}=\alpha x_{t}+(1-\alpha) s_{t-1}, 1>0$

OR

$S_{1}=Y_{1}$ 
For $\mathrm{t}>1, S_{t}=\alpha \cdot Y_{t}+(1-\alpha) \cdot S_{t-1}$

OR

Where $F_{t}=F_{(t-1)}+\alpha\left(\mathrm{A}_{(t-1)}-F_{(t-1)}\right)$

$\mathrm{F}=$ Forecast

$\boldsymbol{\alpha}=$ Coefficient

$\mathrm{t}=$ Time

$\mathrm{A}=$ Actual value

\section{RESULTS}

This section describes the results of the study in which different statistical data were analyzed for area, production and yield of wheat crop.
Trend analysis for moving averages of wheat area of Sindh Province: Table one shows three, five- and seven-years moving average of wheat area for last thirty years. The data for 3-years moving averages for area indicates minimum value of 849.87 hectares and maximum 1129.4 hectares during 1984-2014. The data for 5-years moving averages for area indicates minimum value of 863.04 hectares and maximum 1111.58 hectares during 1984-2014. The data for 7-years moving averages for area indicates minimum value of 890.09 hectares and maximum 1109.6 hectares during 1984-2014.

Table-1 Computation of moving averages of wheat area of Sindh Province

\begin{tabular}{|c|c|c|c|c|c|c|c|}
\hline \multirow{2}{*}{$\begin{array}{c}\text { Years } \\
(\mathbf{T})\end{array}$} & \multirow{2}{*}{$\begin{array}{c}\text { Wheat area in } \\
\text { "000" hectares } \\
\left(\mathbf{Y}_{t}\right)\end{array}$} & \multicolumn{2}{|c|}{3 years-moving } & \multicolumn{2}{|c|}{5 years-moving } & \multicolumn{2}{|c|}{7 years-moving } \\
\hline & & Total & $\begin{array}{c}\text { Average } \\
\text { Forecast } \\
\end{array}$ & Total & $\begin{array}{c}\text { Average } \\
\text { Forecast } \\
\end{array}$ & Total & $\begin{array}{c}\text { Average } \\
\text { Forecast } \\
\end{array}$ \\
\hline 1984-85 & 1029.80 & - & - & - & - & - & - \\
\hline $1985-86$ & 1030.80 & - & - & - & - & - & - \\
\hline $1986-87$ & 1036.00 & 1032.20 & - & - & - & - & - \\
\hline $1987-88$ & 1024.80 & 1030.53 & 1032.20 & - & - & - & - \\
\hline $1988-89$ & 1045.20 & 1035.33 & 1030.53 & 1033.32 & - & - & - \\
\hline $1989-90$ & 1044.70 & 1038.23 & 1035.33 & 1036.30 & 1033.32 & - & - \\
\hline 1990-91 & 1053.50 & 1047.80 & 1038.23 & 1040.84 & 1036.30 & 1037.83 & - \\
\hline $1991-92$ & 1058.40 & 1052.20 & 1047.80 & 1045.32 & 1040.84 & 1041.91 & 1037.83 \\
\hline $1992-93$ & 1103.70 & 1071.87 & 1052.20 & 1061.10 & 1045.32 & 1052.33 & 1041.91 \\
\hline 1993-94 & 1105.60 & 1089.23 & 1071.87 & 1073.18 & 1061.10 & 1062.27 & 1052.33 \\
\hline 1994-95 & 1063.00 & 1090.77 & 1089.23 & 1076.84 & 1073.18 & 1067.73 & 1062.27 \\
\hline $1995-96$ & 1065.00 & 1077.87 & 1090.77 & 1079.14 & 1076.84 & 1070.56 & 1067.73 \\
\hline 1996-97 & 1106.80 & 1078.27 & 1077.87 & 1088.82 & 1079.14 & 1079.43 & 1070.56 \\
\hline $1997-98$ & 1120.20 & 1097.33 & 1078.27 & 1092.12 & 1088.82 & 1088.96 & 1079.43 \\
\hline 1998-99 & 1123.70 & 1116.90 & 1097.33 & 1095.74 & 1092.12 & 1098.29 & 1088.96 \\
\hline 1999-00 & 1144.20 & 1129.37 & 1116.90 & 1111.98 & 1095.74 & 1104.07 & 1098.29 \\
\hline $2000-01$ & 810.700 & 1026.20 & 1129.37 & 1061.12 & 1111.98 & 1061.94 & 1104.07 \\
\hline 2001-02 & 875.200 & 943.367 & 1026.20 & 1014.80 & 1061.12 & 1035.11 & 1061.94 \\
\hline $2002-03$ & 863.700 & 849.867 & 943.367 & 963.500 & 1014.80 & 1006.36 & 1035.11 \\
\hline 2003-04 & 878.200 & 872.367 & 849.867 & 914.400 & 963.500 & 973.700 & 1006.36 \\
\hline 2004-05 & 887.400 & 876.433 & 872.367 & 863.040 & 914.400 & 940.443 & 973.700 \\
\hline $2005-06$ & 933.200 & 899.600 & 876.433 & 887.540 & 863.040 & 913.229 & 940.443 \\
\hline $2006-07$ & 982.200 & 934.267 & 899.600 & 908.940 & 887.540 & 890.086 & 913.229 \\
\hline 2007-08 & 989.900 & 968.433 & 934.267 & 934.180 & 908.940 & 915.686 & 890.086 \\
\hline 2008-09 & 1031.40 & 1001.17 & 968.433 & 964.820 & 934.180 & 938.000 & 915.686 \\
\hline 2009-10 & 1092.30 & 1037.87 & 1001.17 & 1005.80 & 964.820 & 970.657 & 938.000 \\
\hline 2010-11 & 1144.40 & 1089.37 & 1037.87 & 1048.04 & 1005.80 & 1008.69 & 970.657 \\
\hline 2011-12 & 1049.20 & 1095.30 & 1089.37 & 1061.44 & 1048.04 & 1031.80 & 1008.69 \\
\hline $2012-13$ & 1090.60 & 1094.73 & 1095.30 & 1081.58 & 1061.44 & 1054.29 & 1031.80 \\
\hline $2013-14$ & 1121.60 & 1087.13 & 1094.73 & 1099.62 & 1081.58 & 1074.20 & 1054.29 \\
\hline $2014-15$ & & & 1087.13 & & 1099.62 & & 1074.20 \\
\hline
\end{tabular}

The results showed that the minimum wheat area was found in 2001-02 and was maximum in 199899 for 3-years moving averages. For 5-years moving averages minimum wheat area was found in 2004-05 and was maximum in 1999-2000.For 7years moving averages minimum wheat area was found in 2006-07 and was maximum in 1999-2000. Furthermore, in accordance with year-wise increased and decreased area cultivation, it was recorded that area under cultivation was varying in different years. However, area mostly increased from 1987-88 to till 2000-01. Again, it decreased in the year of 2001-02 to 2008-09. Then started increasing from 2009-10 to 2011-12. The forecast for area from the 3,5- and 7-years moving 
averages was 1087.13, 1099.62 and 1074.20 hectares in the previous 2014-15 years.

Trend analysis for moving averages of wheat production of Sindh Province: Table two shows three, five and seven years moving average of wheat production for last thirty years. The data for 3 -years moving averages for production indicates minimum value of 2065.57 tonnes and maximum
3917.50 tonnes during 1984-2014. The data for 5years moving averages for production indicates minimum value of 2117.7 tonnes and maximum 3740.8 tonnes during 1984-2014. The data for 7years moving averages for area indicates minimum value of 2154.3 tonnesand maximum 3469.4tonnesduring 1984-2014.

Table-2 Computation of moving averages of wheat production of Sindh Province

\begin{tabular}{|c|c|c|c|c|c|c|c|}
\hline \multirow{2}{*}{$\begin{array}{l}\text { Years } \\
(\mathbf{T})\end{array}$} & \multirow{2}{*}{$\begin{array}{c}\text { Wheat area } \\
\text { in "000" } \\
\text { hectares } \\
\left(\mathbf{Y}_{t}\right)\end{array}$} & \multicolumn{2}{|c|}{3 years-moving } & \multicolumn{2}{|c|}{5 years-moving } & \multicolumn{2}{|c|}{7 years-moving } \\
\hline & & Total & $\begin{array}{l}\text { Average } \\
\text { (Trend) }\end{array}$ & Total & $\begin{array}{l}\text { Average } \\
\text { (Trend) }\end{array}$ & Total & $\begin{array}{c}\text { Average } \\
\text { (Trend) }\end{array}$ \\
\hline $1984-85$ & 1945.80 & - & - & - & - & - & - \\
\hline $1985-86$ & 2078.70 & - & - & - & - & - & - \\
\hline $1986-87$ & 2172.20 & 2065.57 & - & - & - & - & - \\
\hline $1987-88$ & 2211.50 & 2154.13 & 2065.57 & - & - & - & - \\
\hline 1988-89 & 2180.40 & 2188.03 & 2154.13 & 2117.72 & - & - & - \\
\hline $1989-90$ & 2360.60 & 2250.83 & 2188.03 & 2200.68 & 2117.72 & - & - \\
\hline $1990-91$ & 2130.90 & 2223.97 & 2250.83 & 2211.12 & 2200.68 & 2154.30 & - \\
\hline $1991-92$ & 2274.50 & 2255.33 & 2223.97 & 2231.58 & 2211.12 & 2201.26 & 2154.30 \\
\hline $1992-93$ & 2365.40 & 2256.93 & 2255.33 & 2262.36 & 2231.58 & 2242.21 & 2201.26 \\
\hline $1993-94$ & 2418.00 & 2352.63 & 2256.93 & 2309.88 & 2262.36 & 2277.33 & 2242.21 \\
\hline 1994-95 & 2116.60 & 2300.00 & 2352.63 & 2261.08 & 2309.88 & 2263.77 & 2277.33 \\
\hline $1995-96$ & 2117.80 & 2217.47 & 2300.00 & 2258.46 & 2261.08 & 2254.83 & 2263.77 \\
\hline 1996-97 & 2319.10 & 2184.50 & 2217.47 & 2267.38 & 2258.46 & 2248.90 & 2254.83 \\
\hline $1997-98$ & 2344.80 & 2260.57 & 2184.50 & 2263.26 & 2267.38 & 2279.46 & 2248.90 \\
\hline $1998-99$ & 2443.90 & 2369.27 & 2260.57 & 2268.44 & 2263.26 & 2303.66 & 2279.46 \\
\hline 1999-00 & 2659.40 & 2482.70 & 2369.27 & 2377.00 & 2268.44 & 2345.66 & 2303.66 \\
\hline $2000-01$ & 2675.10 & 2592.80 & 2482.70 & 2488.46 & 2377.00 & 2382.39 & 2345.66 \\
\hline 2001-02 & 3001.30 & 2778.60 & 2592.80 & 2624.90 & 2488.46 & 2508.77 & 2382.39 \\
\hline 2002-03 & 2226.50 & 2634.30 & 2778.60 & 2601.24 & 2624.90 & 2524.30 & 2508.77 \\
\hline 2003-04 & 2101.00 & 2442.93 & 2634.30 & 2532.66 & 2601.24 & 2493.14 & 2524.30 \\
\hline 2004-05 & 2109.20 & 2145.57 & 2442.93 & 2422.62 & 2532.66 & 2459.49 & 2493.14 \\
\hline 2005-06 & 2172.20 & 2127.47 & 2145.57 & 2322.04 & 2422.62 & 2420.67 & 2459.49 \\
\hline 2006-07 & 3409.20 & 2563.53 & 2127.47 & 2403.62 & 2322.04 & 2527.79 & 2420.67 \\
\hline 2007-08 & 3411.40 & 2997.60 & 2563.53 & 2640.60 & 2403.62 & 2632.97 & 2527.79 \\
\hline 2008-09 & 3540.20 & 3453.60 & 2997.60 & 2928.44 & 2640.60 & 2709.96 & 2632.97 \\
\hline $2009-10$ & 3703.10 & 3551.57 & 3453.60 & 3247.22 & 2928.44 & 2920.90 & 2709.96 \\
\hline $2010-11$ & 4287.90 & 3843.73 & 3551.57 & 3670.36 & 3247.22 & 3233.31 & 2920.90 \\
\hline 2011-12 & 3761.50 & 3917.50 & 3843.73 & 3740.82 & 3670.36 & 3469.36 & 3233.31 \\
\hline 2012-13 & 3698.70 & 3916.03 & 3917.50 & 3798.28 & 3740.82 & 3687.43 & 3469.36 \\
\hline 2013-14 & 3598.70 & 3686.30 & 3916.03 & 3809.98 & 3798.28 & 3714.50 & 3687.43 \\
\hline 2014-15 & & & 3686.30 & & 3809.98 & & 3714.50 \\
\hline
\end{tabular}

It was seen from the figures that the minimum wheat area was found in 1987-88 and was maximum in 2011-12 for 3-years moving averages. For 5-years moving averages minimum wheat area was found in 1988-89 and was maximum in 2011-12. For 7-years moving averages minimum wheat area was found in 1991-92 and was maximum in 201112. The results further indicated that the wheat product ion was increased in a linear trend from 1991-92 to till 2011-12 and did not turn down even upto 2012. The forecast for production from the 3,5 and 7 years moving averages was $3686.30,3809.98$ and 3714.50 tonnes in the previous 2014-15 years.

Trend analysis for moving averages of wheat yield of Sindh Province: Table three shows three, five and seven years moving average of wheat yield for last thirty years. The data for 3-years moving averages for yield 
indicates minimum value of 2071.7 tonnes and maximum 3574.0 tonnes during 1984-2014. The data for 5-years moving averages for production indicates minimum value of 2107.8 tonnes and maximum 3520.0 tonnes during
1984-2014. The data for 7-years moving averages for area indicates minimum value of 2120.0 tonnes and maximum 3414.0 tonnes during 1984-2014.

Table-3 Computation of moving averages of wheat yield of Sindh Province

\begin{tabular}{|c|c|c|c|c|c|c|c|c|}
\hline \multirow{2}{*}{$\begin{array}{l}\text { Years } \\
\text { (T) }\end{array}$} & \multirow{2}{*}{\multicolumn{2}{|c|}{$\begin{array}{l}\text { Wheat area } \\
\text { in "000" } \\
\text { hectares }\left(\mathbf{Y}_{t}\right)\end{array}$}} & \multicolumn{2}{|c|}{3 years-moving } & \multicolumn{2}{|c|}{5 years-moving } & \multicolumn{2}{|c|}{7 years-moving } \\
\hline & & & Total & \begin{tabular}{|l|l|} 
Average \\
Forecast
\end{tabular} & Total & \multirow{2}{*}{$\begin{array}{c}\text { Average } \\
\text { Forecast } \\
-\end{array}$} & Total & $\begin{array}{l}\text { Average } \\
\text { Forecast } \\
\end{array}$ \\
\hline 1984-85 & 2019 & - & & - & - & & - & - \\
\hline $1985-86$ & 2107 & - & & - & - & - & - & - \\
\hline 1986-87 & 2135 & & 2087.00 & - & - & - & - & - \\
\hline $1987-88$ & 2128 & & 2123.33 & 2087.00 & - & - & - & - \\
\hline 1988-89 & 2259 & & 2174.00 & 2123.33 & 2129.60 & - & - & - \\
\hline 1989-90 & 2040 & & 2142.33 & 2174.00 & 2133.80 & 2129.60 & - & - \\
\hline $1990-91$ & 2159 & & 2152.67 & 2142.33 & 2144.20 & 2133.80 & 2121.00 & - \\
\hline $1991-92$ & 2235 & & 2144.67 & 2152.67 & 2164.20 & 2144.20 & 2151.86 & 2121.00 \\
\hline 1992-93 & 2191 & & 2195.00 & 2144.67 & 2176.80 & 2164.20 & 2163.86 & 2151.86 \\
\hline 1993-94 & 1914 & & 2113.33 & 2195.00 & 2107.80 & 2176.80 & 2132.29 & 2163.86 \\
\hline 1994-95 & 2182 & & 2095.67 & 2113.33 & 2136.20 & 2107.80 & 2140.00 & 2132.29 \\
\hline 1995-96 & 2185 & & 2093.67 & 2095.67 & 2141.40 & 2136.20 & 2129.43 & 2140.00 \\
\hline 1996-97 & 2119 & & 2162.00 & 2093.67 & 2118.20 & 2141.40 & 2140.71 & 2129.43 \\
\hline $1997-98$ & 2208 & & 2170.67 & 2162.00 & 2121.60 & 2118.20 & 2147.71 & 2140.71 \\
\hline 1998-99 & 2374 & & 2233.67 & 2170.67 & 2213.60 & 2121.60 & 2167.57 & 2147.71 \\
\hline $1999-00$ & 2381 & & 2321.00 & 2233.67 & 2253.40 & 2213.60 & 2194.71 & 2167.57 \\
\hline $2000-01$ & 2623 & & 2459.33 & 2321.00 & 2341.00 & 2253.40 & 2296.00 & 2194.71 \\
\hline 2001-02 & 2746 & & 2583.33 & 2459.33 & 2466.40 & 2341.00 & 2376.57 & 2296.00 \\
\hline $2002-03$ & 2401 & & 2590.00 & 2583.33 & 2505.00 & 2466.40 & 2407.43 & 2376.57 \\
\hline 2003-04 & 2442 & & 2529.67 & 2590.00 & 2518.60 & 2505.00 & 2453.57 & 2407.43 \\
\hline 2004-05 & 2473 & & 2438.67 & 2529.67 & 2537.00 & 2518.60 & 2491.43 & 2453.57 \\
\hline 2005-06 & 2827 & & 2580.67 & 2438.67 & 2577.80 & 2537.00 & 2556.14 & 2491.43 \\
\hline 2006-07 & 3471 & & 2923.67 & 2580.67 & 2722.80 & 2577.80 & 2711.86 & 2556.14 \\
\hline 2007-08 & 3446 & & 3248.00 & 2923.67 & 2931.80 & 2722.80 & 2829.43 & 2711.86 \\
\hline $2008-09$ & 3432 & & 3449.67 & 3248.00 & 3129.80 & 2931.80 & 2927.43 & 2829.43 \\
\hline 2009-10 & 3390 & & 3422.67 & 3449.67 & 3313.20 & 3129.80 & 3068.71 & 2927.43 \\
\hline 2010-11 & 3747 & & 3523.00 & 3422.67 & 3497.20 & 3313.20 & 3255.14 & 3068.71 \\
\hline 2011-12 & 3585 & & 3574.00 & 3523.00 & 3520.00 & 3497.20 & 3414.00 & 3255.14 \\
\hline 2012-13 & 3600 & & 3644.00 & 3574.00 & 3550.80 & 3520.00 & 3524.43 & 3414.00 \\
\hline 2013-14 & 3400 & & 3528.33 & 3644.00 & 3544.40 & 3550.80 & 3514.29 & 3524.43 \\
\hline & & & & 3528.33 & & 3544.40 & & 3514.29 \\
\hline
\end{tabular}

It was noted from the facts stated above that the minimum wheat yield were recorded during the years (1996-97) and was maximum during (201112) for 3-years moving averages. For 5-years moving averages minimum wheat yield was created in the years 1994-95 and was maximum value for wheat production in Sindh province was determined during 2011-12. For 7-years moving averages minimum wheat yield was found in 199596 and was maximum in 2011-12. On the basis of above figures it was examined that wheat yield was continuously increased in a linear trend from 198485 to till 2011-12. The forecast for yield from the
3, 5 and 7 years moving averages was 3528.33 , 3544.40 and 3514.29 tonnes in the previous 201415 years.

Trend analysis of wheat area through exponential smoothing: The below figure 1 reveals that, although there are slightly changes in area under cultivation, however, over the time of 4 decades the area is almost same with slight difference. Therefore, exponential model could not stand with the data of area under cultivation. The rationale behind stagnant data sown could be due to shortage of irrigation of water. 


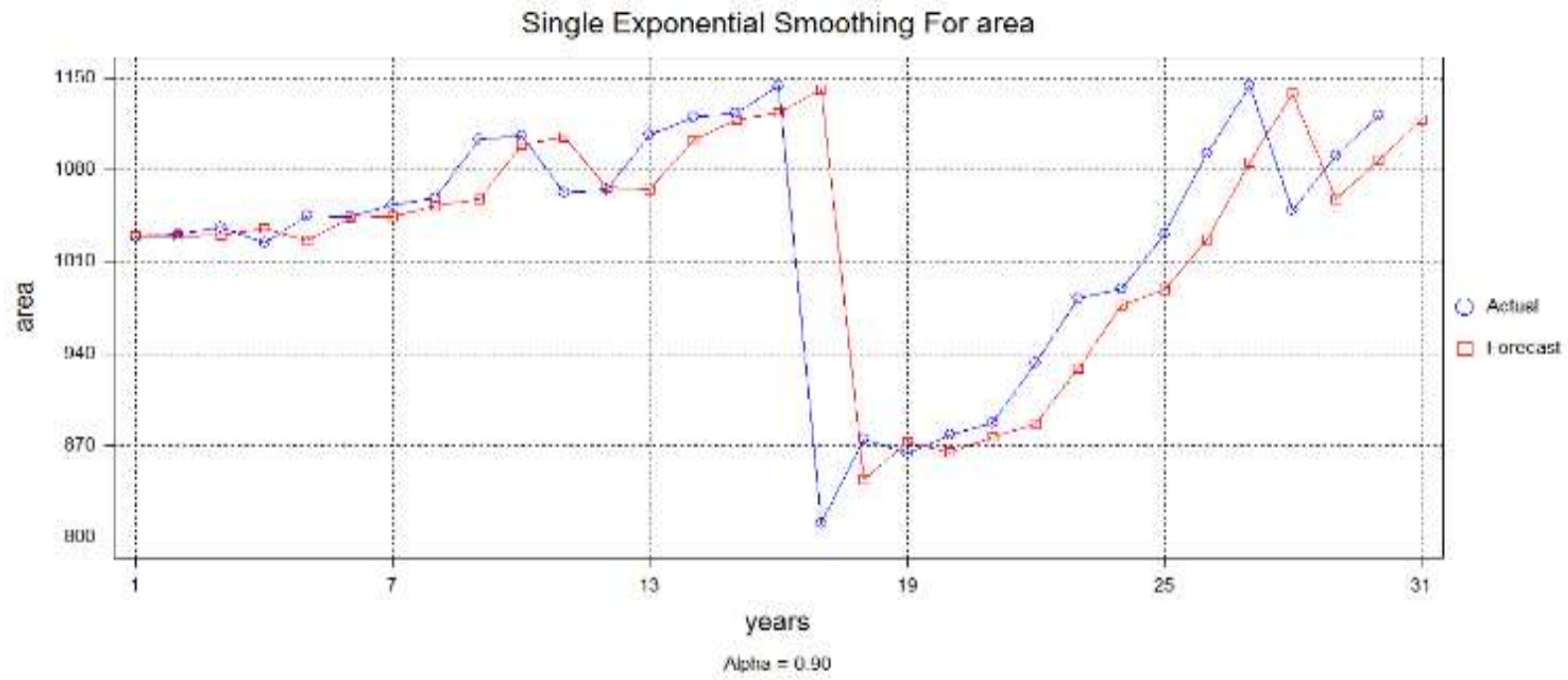

Figure 1. Graph showing exponential smoothing of wheat area

Smoothing Constant

Mean Squared Error (MSE)

Mean Absolute Deviation (MAD)
0.90
4773.36
35.5342

Trend analysis of wheat production through exponential smoothing:The below figure 2 reveals that there is increasing trend of wheat production over the last 4 decades, sharp declined was recorded during 2002 to 2004. However, production increased at the faster pace afterward and reached its optimum level during 2008-09. As $\begin{array}{ll}\text { Mean Percentage Error (MPE) } & 0.01 \\ \text { Forecast } & 1118.18\end{array}$

wheat production is the multiplication of area and yield per acre, therefore increasing trend of wheat production reveals that one of two factors has increased. As discussed in the previous graph that area remain stagnant over the 4 decades and yield increased. Resultantly increase in production is only due to increase in yield

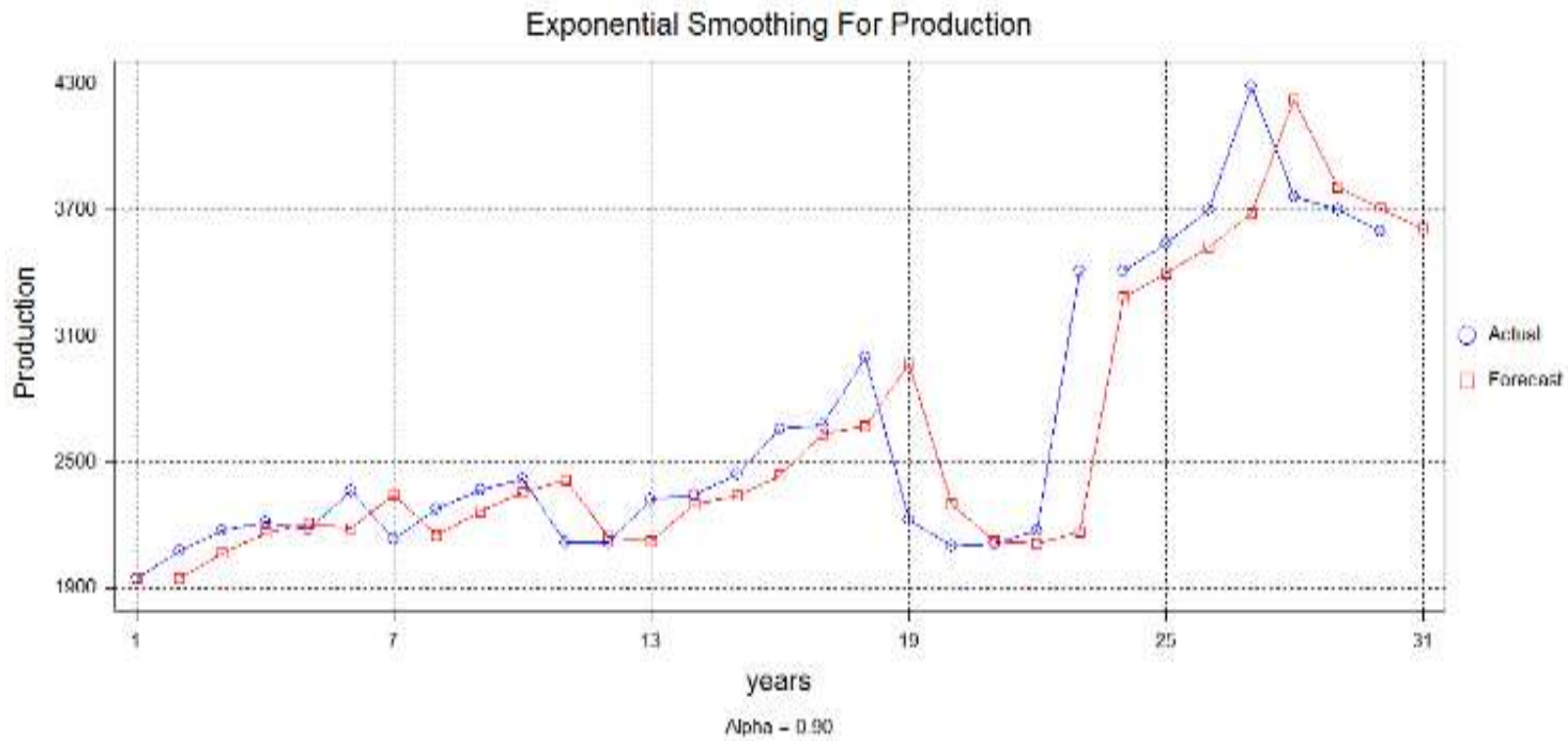

Figure 2. Graph showing exponential smoothing of wheat production

Smoothing Constant

Mean Squared Error (MSE)

0.90

108378

Mean Absolute Deviation (MAD) 208.377
Mean Percentage Error (MPE) 1.56

Forecast

3609.79 
Trend analysis of wheat yield through exponential smoothing: The below figure 3 reveals that there is almost increasing trend of yield over the last 4-decades. But, slightly decreasing of yield observed in 2002 to 2005 .
As prior graph shows area is approximately constant. However, the proportion of yield increased rapidly in half of the last five years. New and latest quality of seed rate is introduced in the wheat growing areas.

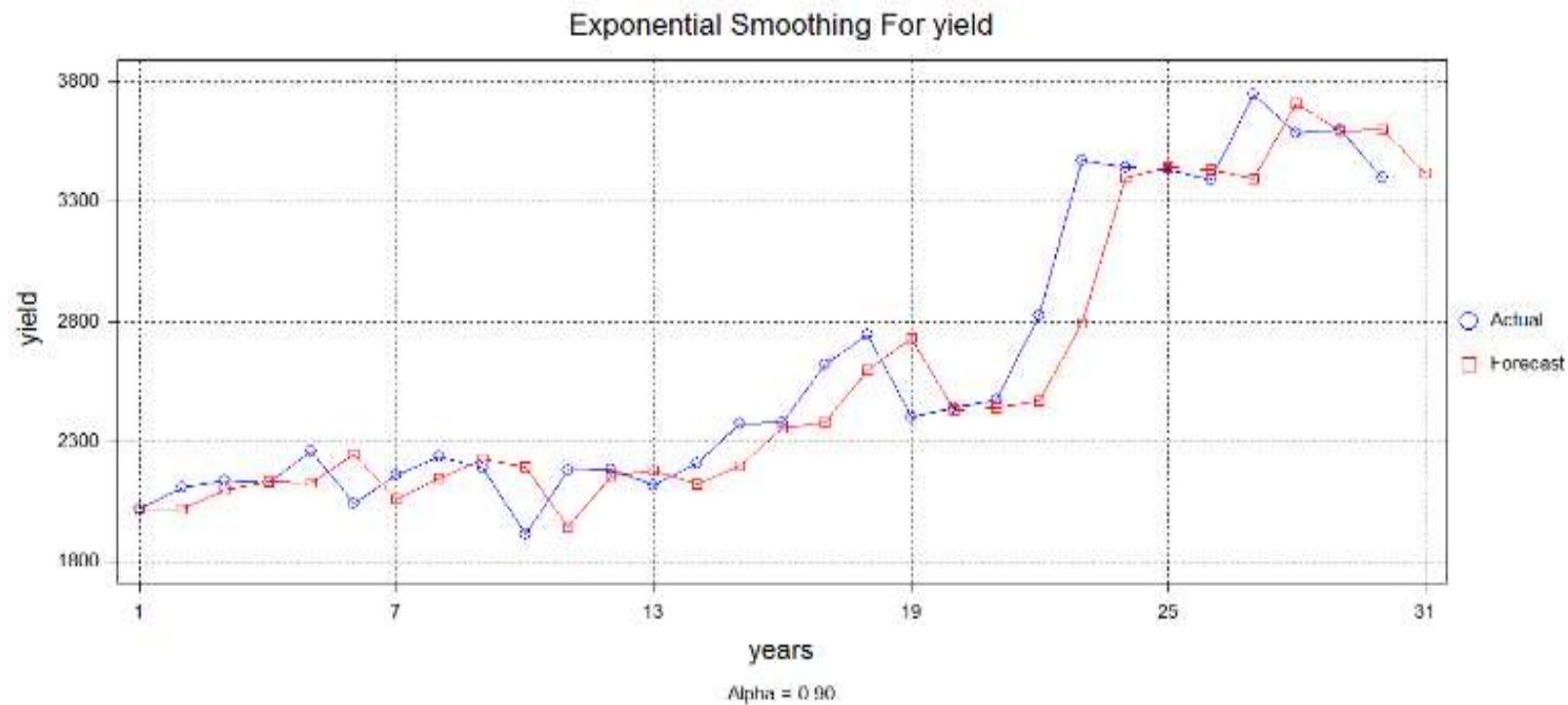

Figure 3. Graph showing exponential smoothing of wheat yield.

Smoothing Constant

Mean Squared Error (MSE)

Mean Absolute Deviation (MAD)

0.90

41036.7

138.417

\section{Discussion}

The results were summarized in this section. The data for 3-years moving averages for area indicates minimum value of 849.87 hectares and maximum 1129.4 hectares during 1984-2014. The data for 5-years moving averages for area indicates minimum value of 863.04 hectares and maximum 1111.58 hectares during 1984-2014. The data for 7years moving averages for area indicates minimum value of 890.09 hectares and maximum 1109.6 hectares during 1984-2014. 3-years moving averages for production indicates minimum value of 2065.57 tonnes and maximum 3917.50 tonnes during 19842014. The data for 5-years moving averages for production indicates minimum value of 2117.7 tonnes and maximum 3740.8 tonnes during 1984-2014. The data for 7-years moving averages for area indicates minimum value of 2154.3 tonnes and maximum 3469.4 tonnes during 1984-2014. 3-years moving
Mean Percentage Error (MPE)

Forecast

averages for yield indicates minimum value of 2071.7 tonnes and maximum 3574.0 tonnes during 1984-2014. The data for 5-years moving averages for production indicates minimum value of 2107.8 tonnes and maximum 3520.0 tonnes during 1984-2014. The data for 7-years moving averages for area indicates minimum value of 2120.0 tonnes and maximum 3414.0 tonnes during 1984-2014.

The forecast for area from the 3, 5- and 7-years moving averages was 1087.13, 1099.62 and 1074.20 hectares in the previous 2014-15 years. The forecast for production from the 3 , 5- and 7-years moving averages was 3686.30 , 3809.98 and 3714.50 tonnes in the previous 2014-15 years. The forecast for yield from the 3, 5- and 7-years moving averages was $3528.33,3544.40$ and 3514.29 tonnes in the previous 2014-15 years. In this study exponential smoothing analysis revealed that trends for area, production and yield are in increasing trend. But forecasting shows that 
area is increased whenever production and yield are decreased in 2014-2015 year.

\section{Conclusions}

It is concluded that area, production and yield under wheat cultivation showed an increasing and decreasing trend. So, in case of forecasting, the area and production under wheat cultivation was increase in the coming year, but the yield under wheat cultivation was considerably decreased due to shortage of irrigation water. In this study by exponential smoothing analysis revealed that trends for area, production and yield are in increasing trend. But forecasting shows that area is increased whenever production and yield are decreased in 2014-2015.

\section{Suggestion}

It is suggested that government needs accurate and advance information about wheat crop. Therefore, accurate forecasting of wheat area, production and yield may support the policy makers and planners for making policy decision regarding supply, demand and import of wheat in the province.

\section{References}

Ahmad, D., Chani, M. I., \& Humayon, A. (2017). Major Crops Forecasting Area, Production and Yield Evidence from Agriculture Sector of Pakistan. Sarhad Journal of Agriculture. 33: 385- 396.

Amin, M., Amanullah M., and Akbar A. (2014). Time Series Modeling for Forecasting Wheat Production of Pakistan, the journal of animal and plant science, 24 (5): 1444-1451.

Aslam, M. (2016). Agricultural productivity current scenario, constraints and future prospects in Pakistan. Sarhad Journal of Agriculture, 32 (4): 289-303.

GOP (Government of Pakistan), (2019). Economic Survey of Pakistan. Ministry of Finance Division, Economic Advisor's Wing, Islamabad, Pakistan.

GOP (Government of Pakistan), (2015). Economic Survey of Pakistan. Ministry of Finance

$$
\text { Division, }
$$

Economic Advisor's Wing, Islamabad, Pakistan.

GOP (Government of Pakistan). (2017). Economic Survey of Pakistan. Ministry of Finance Division, Economic Advisor's Wing, Islamabad, Pakistan.

Hamid, A., and Ahmad, N. (2001). Integrated Plant Nutrient System: Development and Rural Poverty Alleviation. In: Regional Workshop on Integrated Plant Nutrient System Development and Rural Poverty Alleviation 2001, Bangkok, Thailand, $P$ 18-20 September.

Hamid, N., Thomas, P., Alberto V., and Suzanne, G. (1987). The wheat economy of Pakistan setting and prospects. International Food Policy Research Institute, Ministry of Food and Agriculture, Government of Pakistan, Islamabad, Pakistan.

Hasan, M.F., and K.S. Imai. (2013). Impacts of agricultural extension on crop productivity, poverty and vulnerability: Evidence from Uganda. DP 2012-34. Discussion Paper Series RIEB. Research Institute for Economics and Business Administration. Kobe University, Japan. pp. 32.

Iqbal, M., Z. Hussain and T. Mahmood. (2014). Forecasting trade behaviour of major food crops in four leading SAARC countries. Pakistan Economic and Social Review. 52 (2): 209-226.

Iqbal, N. B. K., M. Asif and S. A. Ahmad. (2005). "Use of the ARIMA Model for Forecasting Wheat Area and Production in Pakistan," Journal of Agriculture and Social Sciences, 1(2): 120-122.

Iqbal, N., K. Bakhsh, K. Maqbool and A.S. Ahmad. (2000). Use of the ARIMA model for forecasting wheat area and production in Pakistan. Int. J. Agri. Biol. 2: 352-354.

Karim, R., A. Awal and M. Akhter. (2005). Forecasting of wheat production in Bangladesh. J. Agri. Soc. Sci. 1: 120122.

Khan, M. A., Tahir, A., Khurshid, N., Iftikhar ul Husnain, M., Ahmed, M., and 
Boughanmi, H. (2020). Sustainability 12: 1216; doi:10.3390/su12031216

Koondhar, M. A., Qiu, L., Magsi, H., Chandio, A. A., and He, G. (2018). Comparing economic efficiency of wheat productivity in different cropping systems of Sindh Province, Pakistan. Journal of the Saudi Society of Agricultural Sciences. 17 (4): 398-407.

Kumar, A., Deepankar, Jaslam, P.K M., and Kumar, A. (2019). Wheat Yield Forecasting in Haryana: A Time Series Approach. Bull. Env. Pharmacol. Life Sci., 8 (3): 63-69.

Magsi, H., Rashid, M. K., Khushik, G. M., Khatyan, M. A., and Babar, M. N. (2018). SALU- Commerce $\&$ Economics Review. 4 (1): 70-77.

Mahmood, N., Arshad, M., Kächele, H., Ma, H., Ullah, A., \& Müller, K. (2019). Wheat yield response to input and socioeconomic factors under changing climate: Evidence from rainfed environments of Pakistan. Science of The Total Environment. 688 (20): 12751285
Masood, A., N. Ellahi and Z. Batool. (2012). Causes of low agricultural output and impact on socio- economic status of farmers: A case study of rural Potohar in Pakistan. Int. J. Basic Appl. Sci. 1 (2): 343-351.

Muhammad, F., M. Siddique, M. Bashir and S. Ahmad. (1992). Forecasting rice production in Pakistan using ARIMA Models. J.Anim.Plant.Sci. 2: 27-31

Muhammad, K. (1989). Description of the historical background of wheat improvement in Baluchistan, Pakistan. Agriculture Research Institute (Sariab, Quetta, Baluchistan, Pakistan).

Qureshi, K., A.B. Akhtar, M. Aslam, A. Ullah and A. Hussain. (1992). An Analysis of the relative contribution of area and yield to Total production of wheat and maize in Pakistan. J. Agri. Sci. 29: 166-169.

Shah, S. A. A., Ali, S., and Jadoon, A. (2018). Growth, Variability and Forecasting of Wheat and Sugarcane Production in Khyber Pakhtunkhwa, Pakistan. Agri Res \& Tech. 18 (2): 556056. 